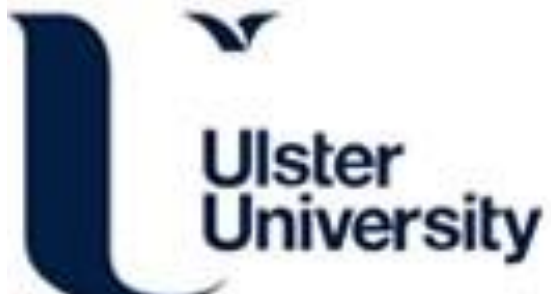

\section{The impact of hearing loss and sensory intervention on the risk of progression to dementia in mild cognitive impairment cases}

Bucholc, M., Ding, X., Wong-Lin, K., McClean, P., Todd, S., \& Maguire, L. (2019). The impact of hearing loss and sensory intervention on the risk of progression to dementia in mild cognitive impairment cases. In Alzheimer's and Dementia (7 ed., Vol. 15, pp. 194-194). Elsevier. https://doi.org/10.1016/j.jalz.2019.06.4524

Link to publication record in Ulster University Research Portal

\section{Published in:}

Alzheimer's and Dementia

Publication Status:

Published (in print/issue): 14/07/2019

DOI:

10.1016/j.jalz.2019.06.4524

\section{Document Version}

Author Accepted version

\section{General rights}

Copyright for the publications made accessible via Ulster University's Research Portal is retained by the author(s) and / or other copyright owners and it is a condition of accessing these publications that users recognise and abide by the legal requirements associated with these rights.

\section{Take down policy}

The Research Portal is Ulster University's institutional repository that provides access to Ulster's research outputs. Every effort has been made to ensure that content in the Research Portal does not infringe any person's rights, or applicable UK laws. If you discover content in the Research Portal that you believe breaches copyright or violates any law, please contact pure-support@ulster.ac.uk. 


\title{
The impact of hearing loss and sensory intervention on the risk of progression to dementia in mild cognitive impairment cases
}

\author{
Magda Bucholc ${ }^{1}$, Xuemei Ding ${ }^{1,2}$, KongFatt Wong-Lin ${ }^{1}$, Paula L. McClean ${ }^{3}$, Stephen Todd ${ }^{4}$, \\ Liam P. Maguire ${ }^{1}$ \\ ${ }^{1}$ Intelligent Systems Research Centre, School of Computing, Engineering \& Intelligent Systems, Ulster \\ University, Magee campus, Northern Ireland, United Kingdom \\ ${ }^{2}$ Fujian Provincial Engineering Technology Research Centre for Public Service Big Data Mining and \\ Application, College of Mathematics and Informatics, Fujian Normal University, Fuzhou, Fujian, China \\ ${ }^{3}$ Northern Ireland Centre for Stratified Medicine, Biomedical Sciences Research Institute, Ulster \\ University, Northern Ireland, United Kingdom \\ ${ }^{4}$ Altnagelvin Area Hospital, Western Health and Social Care Trust, Northern Ireland, United Kingdom
}

\section{Background}

The high prevalence of dementia and hearing impairment in older adults means these two conditions are likely to coexist. In fact, several studies showed that hearing deficits are linked to accelerated cognitive decline and higher risk of developing dementia, possibly through the impact of hearing loss on the cognitive processing load, changes in brain structure/function, or increased social isolation. Still, relatively little research has been conducted to further explore this relationship, and more importantly, to investigate the role of hearing rehabilitative interventions on cognitive function. In our longitudinal study, we examined the effect of hearing loss on cognitive decline of individuals with mild cognitive impairment ( $\mathrm{MCl})$. In addition, we determined the impact of sensory intervention (hearing aids) on the decline in cognitive abilities.

\section{Methods}

The longitudinal National Alzheimer's Coordinating Center (NACC) dataset was used to examine the association between hearing loss and $\mathrm{MCl}$-to-dementia conversion. To determine the exact duration of the $\mathrm{MCl}$ period, only patients that enrolled as cognitively healthy at baseline and converted to dementia were used. Cognition was assessed using the Clinical Dementia Rating Sum of Boxes (CDRSB) score. The annual rate of change in CDRSB was compared for: 1 ) hearing loss absent $(\mathrm{HN})$ vs hearing loss present, hearing aid not used (HL$\mathrm{NA}$ ); and 2) HL-NA vs hearing loss present, hearing aid used (HL-A) using the Wilcoxon rank sum test with continuity correction. The Cox proportional hazards model was developed to study time to incident dementia.

\section{$\underline{\text { Results }}$}

A reduced risk of progressing to dementia was observed for $\mathrm{HN}$ vs HL-NA with hazard ratio $(\mathrm{HR}), 95 \%$ confidence intervals $(95 \% \mathrm{Cl})$ of $0.51,95 \% \mathrm{Cl}(0.26 ; 1.01)\left(p_{\text {log-rank }}=0.05\right)$. A lower risk of $\mathrm{MCl}$-to-dementia progression was observed for HL-NA vs HL-A (HR $=0.28$, $95 \% \mathrm{Cl}(0.11 ; 0.74)\left(p_{\text {log-rank }}=0.006\right)$. Furthermore, the annual rate of change in CDRSB was significantly higher for HL-NA compared to HL-A $(p=0.027)$. 


\section{Conclusion}

The significant impact of $\mathrm{HL}$ and use of hearing aids on the $\mathrm{MCl}$-to-dementia progression was demonstrated. Future work should focus on investigating the effect of $\mathrm{HL}$ on the cognition of healthy individuals as well as on developing audiology assessments for adults with cognitive impairment. 